\title{
A POSIÇÃO ORIGINAL COMO MEDIAÇÃO ENTRE ESTADO DE NATUREZA E IMPERATIVO CATEGÓRICO: RAWLS ENTRE HORBBES E KANT
}

\author{
THE ORIGINAL POSITION AS MEDIATION BETWEEN STATE OF \\ NATURE AND CATEGORICAL IMPERATIVE: RAWLS BETWEEN \\ HOBBES AND KANT
}

\author{
DELAMAR VOLPATO DUTRA ${ }^{1}$
}

(UFSC, Brasil)

\begin{abstract}
The paper presents the concept of natural law in Hobbes, and denies that its content is purely a hypothetical imperative arising from strategic rationality. The study makes use of the Rawls's interpretation to confer moral status to the content of natural laws as they were proposed by Hobbes. For this purpose, Rawls's original position is interpreted as a strategy for contamination of the categorical imperative by hypothetical imperatives. If Kant states that with various limitations the golden rule can be derived from the categorical imperative, then there must be some element in the golden rule that is also in the categorical imperative. The text investigates what would be this element. The text, therefore, presents a reading inspired by Rawls's original position, whose purpose will be to show that the moral reading of Hobbes held, for example, by Taylor, Warrender, Rawls, and Habermas, are defensible, though not for the reasons alleged by some of them. The conclusion is that although could exist agreement concerning the content of what could be called justice or rules of coexistence, there is disagreement over strategies of reasoning to prove those contents.
\end{abstract}

Keywords: Hobbes. Golden rule. Rawls. Original position.

\section{RESUMO}

O texto apresenta o conceito de lei natural em Hobbes e contesta que o conteúdo da mesma seja exclusivamente um imperativo hipotético decorrente da racionalidade estratégica. Aproveita a interpretação de Rawls para conferir um estatuto moral ao conteúdo das leis naturais, tais quais elas foram propostas por Hobbes. Para tal intento, a posição original é lida como uma estratégia de contaminação do imperativo categórico por imperativos hipotéticos. Se Kant afirma que com várias limitações a regra de ouro pode ser derivada do imperativo categórico, então, deve haver algum elemento da regra de outro no imperativo categórico. O texto perscruta qual seria esse elemento. O texto apresenta, portanto, uma leitura inspirada na posição original de Rawls, cuja finalidade será mostrar que as leituras morais de Hobbes sustentadas, por exemplo, por Taylor, Warrender, Rawls e Habermas, são defensáveis, muito embora não pelas razões alegadas por alguns deles. Conclui-se estar em questão, portanto, não uma discordância quanto aos conteúdos do que se poderia chamar justiça ou regras de convivência, mas uma discordância quanto às estratégias de fundamentação.

Palavras-chave: Hobbes. Regra de ouro. Rawls. Posição original.

"A única e verdadeira filosofia moral"

É letra do texto de Hobbes que a ciência da lei moral é "a única e verdadeira filosofia moral": "The laws of nature are immutable and eternal; for injustice, ingratitude, arrogance, 
pride, iniquity, acception of persons, and the rest can never be made lawful. For it can never be that war shall preserve life, and peace destroy it. [...] And the science of them is the true and only moral philosophy" (HOBBES, 1968, chap. XV). Os estudos de Taylor e Warrender chamaram a atenção para o caráter obrigacional da lei natural em Hobbes. Sabidamente, Kant imputara a Hobbes a tese do positivismo moral, haja vista o soberano não poder cometer injustiça (KANT, TP 08: 303-304) ${ }^{2}$, em razão de ser ele a definir o que é a justiça e a injustiça. Taylor distingue, em Hobbes, o problema da fundamentação do dever [why I ought, or am obliged] e o problema da motivação [what inducement] (TAYLOR, 1938, p. 407-408). Por seu turno, Warrender também segue o mesmo caminho. Segundo este último, a fundamentação do dever, a partir da autopreservação, responderia à questão da motivação, mas não responderia à questão do caráter obrigatório da lei natural (WARRANDER, 1957, p. 212-213). Para esses dois comentadores o problema da motivação encontraria uma resposta inequívoca em Hobbes, qual seja, o interesse na autopreservação. Porém, essa não seria uma boa explicação para a fundamentação do próprio dever em questão, ou seja, da obrigação de cumprir a lei. Portanto, não restaria explicado o caráter normativo da lei natural. Haveria, desse modo, um déficit de fundamentação do caráter normativo da lei natural. Como registra Williams, "The logic of Leviathan is itself a kind of morality, although not directly presented as such.” (WILLIAMS, 2003, p.154)

Ao menos duas conclusões podem ser tiradas dessas considerações. A primeira defende que Hobbes sustentou uma teoria moral em sentido estrito, haja vista ele mesmo afirmar isso em seus textos. Portanto, alegam tais comentadores, o fundamento dela deveria residir não na autopreservação, já que esta seria a explicação da motivação, mas em algum outro fator. A tese de Taylor foi a de que o fundamento consistiria em um imperativo categórico da razão. Segundo ele, a vontade boa, tal qual formulada por Kant, já operaria na distinção do De cive entre um homem justo e uma ação justa (HOBBES, 1998, p. 56, p.8586). Ademais, a contradição prática como base do critério de validade da lei já teria sido também antecipada por Hobbes $(1998, \text { p. } 54-55)^{3}$. Por fim, o ponto mais importante de sua interpretação é de que Hobbes consideraria as leis naturais como imperativos categóricos da razão (TAYLOR, 1938, p. 409). Este último ponto teria sido obscurecido pelas declarações do próprio Hobbes, especialmente no Leviathan, de que as leis naturais seriam teoremas da razão (TAYLOR, 1938, p. 409). Sem embargo, "Hobbes always describes the items of the natural law as dictamina, or dictates, never as consilia, or pieces of advice, and the very use of this language implies their imperative character" (TAYLOR, 1938, p. 411). 
Warrender, por seu turno, distingue o aspecto das leis como máximas racionais para a autopreservaçao e o aspecto do caráter obrigatório das mesmas, tendo avançado a tese de que o caráter obrigatório delas seria devido à sua origem divina: "it is only in their aspect of being commands of God that they are laws and hence oblige. Thus the reason why I can do my duty is that I am able [...] to see it as a means to my preservation; but the reason why I ought to do my duty is that God commands it" (WARRENDER, 1957, p. 212-213). De fato, Hobbes afirma:

These dictates of reason men used to call by the name of laws, but improperly: for they are but conclusions or theorems concerning what conduceth to the conservation and defence of themselves; whereas law, properly, is the word $\mathrm{f}$ him that by right hath command over others. But yet if we consider the same theorems as delivered in the word of God that by right commandeth all things, then are they properly called laws (HOBBES, 1968, chap. XV).

A tese de Warrender se baseia, segundo Nagel, na definição hobbesiana de lei: "It is based on Hobbe's definition of law: a law is a command addressed to one previously obliged to obey the commander" (NAGEL, 1959, p. 75). Ora, todos estão obrigados frente a Deus, logo, os seus comandos são leis para nós. Segundo Nagel, com a sua tese do fundamento divino das leis, Warrender visaria a refutar a interpretação de que a obrigação em Hobbes teria seu fundamento no autointeresse: "This functions both as an explanation of the final ground of obligation and as a refutation of the position that obligation in Hobbes is based on selfinterest" (NAGEL, 1959, p. 75).

Warrender sustentara que se a autopreservação fosse um dever, Hobbes tê-la-ia visto como uma lei e não como um direito (WARRENDER, 1957, p. 216). Ademais, o verbo pelo qual a razão comandaria a guerra seria, então, ought e não may/can, como se pode ler no Leviathan (HOBBES, 1968, chap. XIV). ${ }^{4}$ Hobbes sustenta a autopreservação como um direito, porém, direito e dever em relação a uma mesma coisa são inconsistentes, logo, não poderia haver um direito à autopreservaçao: "according to Hobbes we have a right to selfpreservation; but right and duty are in the same matter inconsistent, because right is the liberty to do or forbear, the absence of obligation. Therefore we cannot have a duty to selfpreservation” (NAGEL, 1959, p. 70-71).

A segunda corrente interpretativa foi sustentada por Nagel, em franca crítica a Warrender. Segundo ele, não haveria obrigações morais genuínas no Leviathan, mas só 
considerações de autointeresse racional (NAGEL, 1959, p. 69). As leis naturais seriam morais só aparentemente (NAGEL, 1959, p. 72). Nagel não está sozinho nessa tese. Como já apontado, essa teria sido também a interpretação de Kant ao sustentar a tese do positivismo moral em Hobbes (PAVÃO, 2006). Por seu turno, Watkins igualmente defende essa interpretação. Para ele, as leis de natureza são imperativos hipotéticos assertórios, cujo fim necessário em questão é a autopreservação, o que implicaria que elas não teriam um caráter moral: "this implies that Hobbes's laws of nature do not have a distinctively moral character" (WATKINS, 1973, p. 56).

Ademais, Nagel comunga com a tese de Taylor-Warrender de que a teoria da motivação baseada no autointeresse "is the ruin of any attempt to put a truly moral construction on Hobbes's concept of obligation" (NAGEL, 1959, p. 74), de tal forma que "a genuine feeling of moral obligation can never play a part in their deliberations" (NAGEL, 1959, p. 75). Por isso, Warrender recorreu à tese do comando de Deus. Disso Nagel retira uma consequência que Warrender não retirou, qual seja, a de não haver obrigação moral no Leviathan, mas só prudência: "Given Hobbes's theory of motivation, one cannot expect to find reference to genuine moral obligation in a book in which he is trying to convince people to do certain things; and this, I believe, is why Warrender's attempt is bound to fail" (NAGEL, 1959, p. 81).

O argumento de Warrender que baseia a lei no comando de Deus não procede porque, para Nagel, até a obediência a Deus é fundamentada estrategicamente: "I believe that he considers even our obligation to obey God a prudentially grounded one" (NAGEL, 1959, p. 76). Segundo a sua interpretação, o fundamento da lei natural em Hobbes não é Deus, mas aquilo que ela evita ou que ela propicia: "He says that the laws of nature are immutable and eternal because war will always destroy life and peace will always preserve it, not because God will never change His instructions" (NAGEL, 1959, p. 80). Portanto, “As an attempt to analyze moral concepts Leviathan fails" (NAGEL, 1959, p. 82).

Não obstante, uma alegação de Nagel contra Warrender poderia ser usada contra ele mesmo. Ele afirma: "Nowhere does Hobbes say that only the commands of an authority can be obligatory. All he says is that only the commands of an authority can be laws" (NAGEL, 1959, p. 76). Na verdade, o que tal formulação aponta é para uma distinção no caráter vinculante da obrigação, ou seja, ela pode vincular interna ou externamente. O que Hobbes afirma é que a lei natural vincula internamente, mas não externamente, para o que precisaria da espada. Assim, é plausível distinguir o vínculo que a lei estabelece, ou seja, o seu caráter 
obrigacional, e os motivos para o seu cumprimento. Por exemplo, um contrato cria um vínculo entre as partes, ou seja, algo que é lei para elas. O motivo para cumprir o vínculo, cumprir a lei, é um outro elemento. Kant muito bem anotou que a lei é um mero conhecimento teórico (KANT, 2005, p. 218; RL, AA 06: 218). A partir dessa clara distinção que Kant faz, a posição de Nagel pode ser avaliada como sendo uma vitima da sua própria confusão entre motivação e lei moral. Ora, segundo Kant, até uma raça de demônios pode cumprir normas com conteúdo moral, ou com conteúdo prático ditado pela razão prática pura (KANT, 2008, p. 29; ZeF, AA 08: 366). Ou seja, do fato de as normas poderem ser cumpridas por autointeresse, ou mesmo só por autointeresse, não se segue que isso afete o seu conteúdo normativo.

\section{O "imperativo categórico dentro de uma estrutura empírica"}

A argumentação acima serviu para avançar duas teses. A primeira, contra a interpretação de Kant e de Nagel, é a de que há um conteúdo moral incrustado na lei natural tal qual formulada por Hobbes. A segunda tese é a de que as soluções apontadas para dar conta de tal caráter normativo da lei natural são inadequadas, tanto por Taylor quanto por Warrender.

A tese que se pretende defender é a de que a argumentação rawlsiana com relação à posição original se constituiria em uma tentativa de unir Hobbes e Kant. Intenta-se interpretar o argumento da posição original de Rawls como uma possibilidade de vestir o imperativo categórico com trajes empíricos assemelhados ao estado de natureza de Hobbes. Com isso, busca-se provar que Rawls foi capaz de aproximar o conteúdo da lei natural ao conteúdo do imperativo categórico, via uma estratégia que seria comum ao contratualismo em geral.

Com relação a essa hipótese, Kaufman argumentou que a posição original não teria base no imperativo categórico, ou não seria modelada segundo o mesmo, mas teria a sua base na teoria do contrato social de Kant, tal qual ele a teria apresentado no texto Contra Hobbes (KAUFMAN, 2012, p. 231). Segundo ele, a primeira tese seria incorreta (KAUFMAN, 2012, p. 247), embora ela seja a interpretação padrão (KAUFMAN, 2012, p. 233). Portanto, pretende-se fazer uma defesa da tese padrão em relação à interpretação de Rawls, até porque há quem sustente que a ideia de contrato apresentada por Kant na obra a pouco mencionada é de cunho moral, ou seja, não se diferenciaria significativamente do imperativo categórico (HABERMAS, 1994, cap. III; GREGOR, 1963). 
Em relação a esse assunto, Rawls faz duas afirmações que serão consideradas cuidadosamente:

(a) "In justice as fairness the original position of equality corresponds to the state of nature in the traditional theory of the social contract" (RAWLS, 1999, p. 11);

(b) "The original position may be viewed, then, as a procedural interpretation of Kant's conception of autonomy and the categorical imperative within the framework of an empirical theory" (RAWLS, 1999, p. 226).

Sabidamente, Rawls caracteriza a posição original pelo véu de ignorância (RAWLS, 1999, p. 118). O que a posição original propicia ao contratualismo de Rawls é a simetria da ignorância, justamente o que tornará equitativos [fair] o acordo [agreement] ou barganha [bargain] resultantes (RAWLS, 1999, p. 11). É dessa posição que se originarão os princípios que pessoas racionais aceitarão: "These principles are those which rational persons concerned to advance their interests would accept in this position of equality to settle the basic terms of their association" (RAWLS, 1999, p. 120). Aliás, o próprio nome justice as fairness advém justamente desse fator (RAWLS, 1999, p. 11).

Rawls sustenta querer elevar a um nível mais alto de abstração o contratualismo, tal qual encontrado em Locke, Rousseau e Kant (RAWLS, 1999, p. 10). O nome de Hobbes é mencionado em nota à referência anterior como portador de problemas especiais, os quais ele não aponta. Sem embargo dessas considerações, o autor do Leviathan aparece em vários momentos importantes da obra de Rawls, por exemplo, quando ele aproxima o dilema do prisioneiro e o estado de natureza (RAWLS, 1999, p. 238) e, principalmente, quando ele relaciona a posição original e o estado de natureza, como visto acima, ainda que neste último caso a remissão seja indireta. Com isso, é possível perquirir por pontos em comum entre o estado de natureza pensado por Hobbes e o desenho de sua posição original. De fato, se a posição original for considerada a peça central da argumentação de Rawls, em vez de uma peça entre outras, a relação com Hobbes se tornará mais forte (HEDRICK, 2010, p. 55). No prefácio à edição revisada, ele diz que a posição original é uma forma mais geral e abstrata de levar adiante a ideia do contrato social (RAWLS, 1999, p. xii). Ele diz ter revisado Uma teoria da justiça exatamente no que concerne à teoria da decisão racional. Deveras, na mencionada obra, ele afirma: "The theory of justice is a part, perhaps the most significant part, of the theory of rational choice" (RAWLS, 1999, p. 15). Na revisão que ele tece a essa formulação no Liberalismo político, o que ele critica é justamente a ideia de que a justiça 
poderia ser derivada somente desse conceito de decisão racional (RAWLS, 1996, p. 53, n.7). Uma crítica, aliás, que ele já fizera em 1985:

\begin{abstract}
The Reasonable, then, is prior to the Rational, and this gives the priority of right. Thus, it was an error in Theory (and a very misleading one) to describe a theory of justice as part of the theory of rational choice [...] There is no thought of trying to derive the content of justice within a framework that uses an idea of the rational as the sole normative idea. That thought is incompatible with any kind of Kantian view. (RAWLS, 1985, p. 237, n. 20).
\end{abstract}

Desse modo, ele defende a justiça como equidade como uma concepção política de justiça de caráter moral: "a political conception of justice, which is, of course, a moral conception." (RAWLS, 1985, p. 237, n. 20). Seja como for, é possível, então, interpretar a sua empreitada de 1971 justamente como uma teoria da decisão racional, ainda que consista em uma reformulação radical da teoria contratual de Hobbes, exatamente pelo estratagema do véu de ignorância. Aliás, nada impede de pensar que seja a revisão de Rawls de sua própria posição que esteja equivocada, até porque, mesmo depois de sua revisão, Rawls não nega que a posição original possa operacionalizar o ponto de vista moral, desde que pressupostas as condições do véu de ignorância: "Yet even after the revision of the initial goal that the original position was designed to achieve, he has held to the view that the meaning of the moral point of view can be operationalized in this way." (HABERMAS, 1998, p.52).

Se o véu de ignorância introduz limitações no conhecimento que a pessoa tem de si mesma e de suas circunstâncias, não se pode esquecer que tais limitações são o verso da medalha do princípio da incerteza que caracteriza a posição original. Segundo Uma teoria da justice: "The veil of ignorance leads directly to the problem of choice under complete uncertainty" (RAWLS, 1999, p.149), de tal forma que "the two principles are an adequate minimum conception of justice in a situation of great uncertainty" (RAWLS, 1999, p. 153). Ora, mutatis mutandis, isso poderia ser vislumbrado também em Hobbes. A incerteza do resultado da guerra pode ser considerada uma ignorância do que vai ocorrer com a pessoa se ela entrar em uma guerra. Segundo Kavka, a incerteza é a noção chave para explicar o argumento de Hobbes contra o louco, o tolo (KAVKA, 1995, p. 21). Ou seja, ela não pode saber se ela será a vencedora, nem se conseguirá manter a posição de vencedora, como não sabe se será morta. Em uma guerra sempre há a possibilidade da morte. Vale lembrar que é justamente essa possibilidade que dá uma igualdade fundamental ao poder dos corpos. 
Deveras, a incerteza do estado de natureza pode-se extrair do registro de Hobbes no cap. XIII com a expressão medo da morte violenta: "and which is worst of all, continual fear, and danger of violent death; and the life of man, solitary, poor, nasty, brutish, and short" (HOBBES, 1968, cap. XIII). Sabidamente, é isso que justifica contratar com os outros, para trocar a insegurança, o perigo, pela segurança: "And lastly the motive, and end for which this renouncing, and transferring of Right is introduced, is nothing else but the security of a mans person, in his life, and in the means of so preserving life" (HOBBES, 1968, cap. XIV).

$\mathrm{O}$ próprio argumento contra o louco em relação à terceira lei de natureza tem sido compreendido como sendo baseado na incerteza. Com efeito, o cerne do argumento, para Kavka, reside na noção de incerteza. Nesse sentido, esclarece ele, seriam quatro os elementos que caracterizariam a racionalidade baseada na incerteza defendida por Hobbes no argumento contra o louco. Em primeiro lugar, o raciocínio seria sempre prospectivo [forward-looking], ou seja, o adimplemento de um contrato no presente seria sempre avaliado como um "means to securing future cooperation and trust from other people." (KAVKA, 1995, p. 21). Aliás, essa é uma interpretação que analisaria um jogo que se repete, ou seja, não se trataria de um jogo de lance único (MOEHLER, 2009). Em segundo lugar, as escolhas seriam feitas sob a condição de incerteza, melhor dito, os resultados que possivelmente adviriam das escolhas caso a caso não estariam disponíveis (KAVKA, 1995, p. 21). Em terceiro lugar, o jogo "play it safe under uncertainty" seria diferente de um cálculo de utilidade caso a caso:

it is rational to play it safe under uncertainty and avoid risking very bad outcomes in hopes of obtaining uncertain gains. In particular, it is irrational to risk social ostracism by committing an offensive violation of a core moral rule (i.e., a law of nature) in hope of obtaining the relatively small and uncertain gains that might follow from getting away with such a violation. (KAVKA, 1995, p. 21-22)

Portanto, o louco argumentaria a partir do benefício caso a caso e Hobbes responderia em termos de longo prazo. Em quarto lugar, seguir regras rigidamente, a longo prazo, seria mais seguro para a autoconservação:

precommitment (or rigid rule-following) is rational in the following sense: one is likely to do better overall by rigidly following the core moral rules than by calculating acceptable risks on particular occasions, because errors and biases in such calculations will tend toward leading you to take excessive risks in particular 
cases (KAVKA, 1995, p. 21-22).

Em suma, "Since the benefits of violation are uncertain, and the risks of failure are so grave, it is rational, in purely forward-looking terms, to play it safe and follow the generally beneficial third (or other) law of nature" (KAVKA, 1995, p. 21-22). Darwall também argumenta nesse mesmo sentido da incerteza (DARWALL, 1995, p. 76).

Desse modo, o jogo "play it safe under uncertainty" explica não só por que é racional cumprir os contratos no estado civil, mas também por que é racional fazer a guerra no estado de natureza, pois tratar-se-iam de perspectivas de sobrevivência a longo prazo, sob circunstâncias diferentes: no estado de natureza tal perspectiva seria quase zero, mesmo fazendo a guerra, ao passo que no estado civil seria uma perspectiva alta. (KAVKA, 1995, p. 23). Decorre disso que o cumprimento dos contratos ditado pela terceira lei natural, incluso aí o contrato social, é posto como condição para a autoconservação e para a paz.

Guardadas as devidas proporções, acorre o mesmo em Rawls. Por exemplo, a pessoa não sabe se será rica ou pobre, então, ela contratará o P2 [princípio 2 de justiça] para evitar o pior risco que pode acontecer com ela, qual seja, ser pobre. Por isso mesmo, segundo Rawls, as leis de natureza formuladas por Hobbes têm conteúdo e papel de princípios razoáveis, embora sejam justificados por cada um pelo seu interesse na sua autoconservação, o que, aliás, é um ponto comum a todo o contratualismo, incluso o de Rawls (RAWLS, 1999, p. 120), cuja base, como se verá, é a regra de ouro: "Thus the Laws of Nature are reasonable principles. Yet for Hobbes these principles are justified to each individual in view of their having the end of self-preservation" (RAWLS, 2007, p. 65-6).

$\mathrm{Na}$ interpretação de Rawls, a aproximação de Hobbes e de Kant acontece em dois passos. Primeiro, ele traduz Hobbes nos termos da classificação kantiana dos imperativos. Se Hobbes fosse traduzido para tal sistema taxonômico, a leis naturais seriam um imperativo hipotético assertórico (RAWLS, 2007, p.64). Para Kant, tais imperativos valem universalmente pelo fato de todos, por uma necessidade natural, terem o fim real declinado (KANT, 2009, p. 415; GMS, AA 04: 415-6), o qual para Kant reside na felicidade. Seja como for, Hobbes pode ser interpretado como estatuindo a autoconservação como um fim real (RAWLS, 2007, p. 65). Provavelmente, Hobbes consideraria poder imputar a todo corpo humano a finalidade da sua autoconservação (BARBOSA FILHO, 1991, p. 63-75). 
Segundo Rawls, a diferença entre um imperativo categórico e um hipotético reside em como algo é justificado e não na forma ou modo de expressão do comando (RAWLS, 2007, p. 65). Por exemplo, “cumpra as promessas" terá este modo de expressão tanto em um imperativo categórico, quanto em um hipotético. Obviamente, neste último caso o comando será dependente de alguma condição a ser posta como finalidade. Mutatis mutandis, como se verá, com o estabelecimento da finalidade da autoconservação fica determinada a condição segundo a qual a regra de ouro poderá operar para gerar os mesmos conteúdos que seriam gerados pelo imperativo categórico de Kant.

Para que o tratamento da justiça nos termos de uma teoria contratualista possa prosperar é necessário que se esclareça que a distinção entre um imperativo categórico e um imperativo hipotético não necessariamente implica uma diferença de conteúdo nas normas que se seguem de um e de outro, muito embora implique uma diferença no modo como o conteúdo é justificado. Alguém pode pensar o dever de cumprir um contrato com base na sua reputação para o mercado, ou ele pode, em vez disso, pensar que não cumprir as promessas é uma máxima não universalizável, gerando uma inconsistência, sendo, portanto, um dever cumprir as promessas, independentemente de qualquer circunstância (RAWLS, 2007, p. 65). Ou seja, o cumprimento de uma ação por uma razão hipotética, como um meio para o fim que o sujeito se põe, não desdiz a razão categórica objetiva que poderia haver para o cumprimento daquela ação. Se for assim, a contrario sensu, dado o fim pressuposto, dever-se-ia seguir, sob o ponto de vista do conteúdo, exatamente o mesmo que determinaria o imperativo categórico. É desse modo que Rawls interpreta a afirmação de Hobbes no Leviathan no final do cap. XV, segundo a qual as leis naturais seriam só teoremas ou conclusões que conduziriam à autoconservação.

Sabidamente, para Rawls, reasonable, como contraposto a rational, envolve a ideia de reciprocidade, a qual é necessária para haver cooperação social e não só coordenação social (RAWLS, 2007, p. 56). Segundo ele, "all the principles Hobbes calls 'the Laws of Nature' could plausibly be called reasonable principle" (RAWLS, 2007, p. 60), porque eles tornam a vida social possível (RAWLS, 2007, p. 67). Não obstante, como se verá, Rawls é crítico de Hobbes ao concluir que "if moral right and obligation involves grounds different from the Rational, as I believe it does, Hobbes has no place for it in his official view" (RAWLS, 2007, p. 66).

Os conteúdos razoáveis ou morais da lei natural tais quais formulados por Hobbes podem ser averiguados em vários momentos de sua obra. Por exemplo, no De Cive, a lei 
natural é posta como condição da sociedade, da paz humana: "As it was necessary to the conservation of each man, that he should part with some of his Rights, so it is no lesse necessary to the same conservation, that he retain some others, to wit the Right of bodily protection, of free enjoyment of ayre, water, and all necessaries for life" (HOBBES, 1983, chap. I, §1; chap. III, §I, §XIV). Como se pode perceber, as leis naturais são formuladas como imperativos hipotéticos: "the 'ought' of the first law is not a moral command in some theological, or even Kantian, categorical sense. Rather, it is what Kant called a hypothetical imperative. Every man ought to endeavour peace if he wants to secure his life, which, of course, by natural necessity, he does" (HERBERT, 2009, p. 17). Sem embargo dessas considerações, é de se frisar que as motivações pelas quais as leis são seguidas não desfazem a natureza do seu conteúdo. Boa parte das leis morais podem ser seguidas para se ter uma vida segura ou por outras inclinações.

Nesse diapasão, a interpretação não normativa apontada por Herbert, há pouco, como sendo puramente estratégica, pode ser questionada no sentido de que um conteúdo moral é capaz de ser justificado, tanto pelo imperativo categórico, quanto por um imperativo hipotético, este último a depender de um fim real. Ou seja, ao se cumprir uma norma conforme ao dever, o imperativo que opera é o hipotético. O próprio Hobbes não viu problemas em afirmar que as leis de natureza são a filosofia moral: "and therefore the true Doctrine of the Lawes of Nature, is the true Morall Philosophie" (HOBBES, 1968, chap. XV). A excelência dessas leis, ajunta ele, consiste em serem meios para uma vida pacífica, sociável e confortável. Segundo Rawls, tais determinações poderiam ser fundamentadas por um imperativo hipotético, desde que certas pressuposições fossem feitas. Esse seria o caso da posição original que ele desenha.

Com isso, Rawls e Höffe ${ }^{5}$ concordam na afirmativa de que a racionalidade estratégica operante mediante a regra de ouro é capaz de fornecer os conteúdos de igualdade e reciprocidade da lei natural, nesse particular em franca oposição a Habermas (1997, cap III). Para ser preciso, Rawls afirma duas coisas, que Hobbes deriva o razoável do racional e que o razoável tem fundamentos diferentes do racional. Portanto, a argumentação de Hobbes seria falha em relação a duas determinações fundamentais, aquela da obrigação, como já chamara a atenção Nagel, conforme acima exposto, e aquela de um direito moral (RAWLS, 2007, p. 66). Dito claramente, a discordância de Rawls não é com relação ao conteúdo, mas com relação à forma, ou seja, é com relação ao caráter obrigacional, em um sentido para o qual já apontara Nagel, como acima registrado. 
Ora, como o próprio Rawls observa, a lei natural não fundamenta uma obrigação absoluta porque, em primeiro lugar, o seu cumprimento depende do que os outros farão (RAWLS, 2007, p. 66). Ela não é uma obrigação que se cumpre unilateralmente como um dever absoluto, pois fazer isso seria se expor como presa aos outros, como estabelece o cap. XIV do Leviathan. Em segundo lugar, no coração mesmo da teoria de Hobbes, quando ele fundamenta a terceira lei natural em sua resposta ao louco, alega Rawls, Hobbes não desafia a razão pela qual o louco argumenta, mas a matéria de fato: "Hobbes does not argue contra the fool that the fool appeals to the wrong kind of reasons; he disputes the fool's suppositions of fact" (RAWLS, 1999b, p. 70). Deveras, Hobbes alega que a avaliação do louco the favorece somente por acidente:

For the manifestation whereof, we are to consider; First, that when a man doth a thing, which notwithstanding any thing can be foreseen, and reckoned on, tendeth to his own destruction, howsoever some accident which he could not expect, arriving may turne it to his benefit; yet such events do not make it reasonably or wisely done." (HOBBES, 1968, chap. XV)

Logo, se é por acidente que o louco é favorecido, não o por uma avaliação acurada e confiável, mormente a longo prazo.

Com isso, alega Rawls, Hobbes não desfaz a contingência da obrigação em função da autoconservação. A sua hipótese é a de que a razoabilidade exige uma noção de obrigação categórica, no sentido de que pode impingir uma coação absoluta sobre a sensibilidade, o que Hobbes não conseguiria ofertar. Nesse diapasão, ele não comenta a expressão direito moral que parece ser central para a sua argumentação, a não ser para explicar o pensamento de Mill. Não obstante, ela é central para a sua argumentação, pois tem conexão com o conceito de inviolabilidade que sustenta em sua obra magna, como se pode verificar abaixo. Contudo, em The Law of Peoples ele afirma: "Political conceptions of justice are themselves intrinsically moral ideas [...] We must hold fast to the idea of the political as a fundamental category and covering political conceptions of justice as intrinsic moral values" (RAWLS, 1999b, p. 174, n. 91). Não é difícil de sustentar que, em última análise, a sua teoria se constituiria em uma teoria moral do direito (HABERMAS, 1997, p.92), vis-à-vis dos termos nos quais ele mesmo qualifica a sua proposta: 


\begin{abstract}
Once the conception of justice is on hand, however, the ideas of respect and of human dignity can be given a more definite meaning. Among other things, respect for persons is shown by treating them in ways that they can see to be justified. But more than this, it is manifest in the content of the principles to which we appeal. Thus to respect persons is to recognize that they possess an inviolability founded on justice that even the welfare of society as a whole cannot override. It is to affirm that the loss of freedom for some is not made right by a greater welfare enjoyed by others. The lexical priorities of justice represent the value of persons that Kant says is beyond all price. The theory of justice provides a rendering of these ideas $[\ldots]$ (RAWLS, 1999, p. 513, §87).
\end{abstract}

Essas observações não desdizem a interpretação aqui proposta, pois ela diz respeito ao conteúdo, não à forma da obrigação. Em razão da formulação hipotética do imperativo, ainda que com base em um fim real, haverá sempre uma relatividade dependente justamente de tal finalidade. Isso Hobbes tem que conceder. O que ele poderia alegar contra Rawls é se ele é capaz de manter a coerência de uma determinação deontológica estrita mesmo em casos extremos, como aquele do estado de necessidade.

Desse modo, interpretar Hobbes com base em um imperativo hipotético assertórico permite enfraquecer as suas assunções teológicas ou mecânicas, materialistas: "But clearly such a mechanical basis is not essential, and they do not affect the content of these ideas" (RAWLS, 2007, p. 28). Desse modo, o conteúdo normativo depositado nas leis naturais poderia ser averiguado tanto por um imperativo categórico, quanto por um imperativo hipotético, desde que neste último caso seja pressuposta a condição da autoconservação que pudesse ser considerada, na linguagem de Kant, um fim real. De fato, eis o que afirma Rawls em relação ao conteúdo da lei natural: "I don't believe that this [materialism] had any significant influence on the content of what I am calling his secular system" (RAWLS, 2007, p. 29).

Rawls, como sugerido, defende uma solução que abriga a noção de razoabilidade no sistema de Hobbes. Isso é feito pela distinção entre o conteúdo da lei natural, que teria natureza de razoabilidade, quer dizer, envolveria a noção de reciprocidade, e a deliberação dos indivíduos de obedecer a lei, ou seja, a sua motivação, a qual seria racional sob a condição de todos obedecerem-na. Portanto, a obediência aos princípios razoáveis "is rational for each person provided that other persons likewise comply" (RAWLS, 2007, p. 64). Esse é precisamente o papel do soberano, a saber, garantir que muitos sigam as leis, de tal forma que 
se torna racional pautar-se pelos princípios razoáveis. Desse modo, princípios razoáveis seriam justificados em termos do que é racional.

\title{
A regra de ouro
}

Sustenta-se que a compreensão da crítica kantiana à regra de ouro é fundamental para entender a proposta de Rawls. Ora, é o próprio Hobbes quem confessa que a regra de ouro é a suma da lei natural. Ele a cita em sua formulação negativa logo depois da segunda lei natural no cap. XIV do Leviathan. Cita-a também na sua forma positiva como resumo de todas as leis depois da décima nova lei de natureza no cap. XV e, novamente como resumo de todas as leis naturais, na sua forma negativa no cap. XXVI. Por isso, é plausível a hipótese de que a crítica de Kant à regra de ouro deva ser tomada como uma peça central de sua crítica a Hobbes.

Ademais, outros contratualistas mencionam a regra de ouro, como é o caso de Rousseau. Em uma referência $D u$ contrat à vontade geral, Rousseau fala de um "accord admirable de l'intérêt et de la justice", pois "chacun se soumet nécessairement aux conditions qu'il impose aux autres" (ROUSSEAU, 1943, livre II, chap. IV). Sendo a alienação total "a condition est égale pour tous; et la condition étant égale pour tous, nul n'a intérêt de la rendre onéreuse aux autres" (ROUSSEAU, 1943, livre I, chap. VI). Difícil não vislumbrar em tais formulações ecos da regra de ouro.

Eis a crítica de Kant à regra de ouro:

\begin{abstract}
Não se pense que o trivial: quod tibi non vis fieri etc. possa servir aqui de norma ou princípio. Pois ele é, se bem que com diversas restrições, tão-somente derivado daquele; não pode ser uma lei universal, visto que não contém o fundamento dos deveres para consigo mesmo, nem dos deveres do amor aos outros (pois muitos topariam de bom gado que os outros não fizessem o bem desde que pudessem se dispensar de se mostrar benfazejos a eles), nem tampouco, por fim, dos deveres exigíveis de uns para com os outros, pois o criminoso argumentaria com base nisso contra o juiz que lhe dita uma pena, etc. (KANT, 2009, p. 430).
\end{abstract}

Sabidamente, Kant refere a regra de ouro à segunda fórmula do imperativo categórico, aquela do homem como um fim em si mesmo.

Antes de qualquer comentário a essa crítica de Kant, não é sem ironia que a história acuse Kant de ser vítima de algo que ele mesmo objetara tão severamente. É conhecida a crítica de Schopenhaeur, segundo a qual o imperativo categórico seria o princípio básico de 
um sistema do egoísmo racional: "à falta de uma fundamentação real do princípio supremo da moral de Kant, exposta no parágrafo precedente, junta-se, contra a afirmação expressa de Kant, a oculta natureza hipotética do mesmo, graças à qual ele se baseia no puro egoísmo, como sendo o intérprete oculto da ordem dada nele" (SCHOPENHAUER, 2001, p. 72). Isso ocorreria porque na universalidade sempre estariam contidos os interesses de todos, o que transformaria o imperativo categórico em um imperativo hipotético, pois torná-lo-ia dependente da finalidade de atender aos interesses de todos, portanto, inclusive ao interesse do particular (MILL, 2003, p. 183), de tal forma que o imperativo categórico seria uma transposição de interesses particulares para a norma, desde que corretamente considerados. Ou seja, matar é uma máxima que não pode ser universalizada. Maravilhosamente, a maioria das pessoas tem um interesse em não ser morta. Portanto, seria uma ética do egoísmo, ainda que racional, não da compaixão. Sem embargo do afirmado, Schopenhauer deixa de considerar a afirmação kantiana de que é um dever incondicional não tirar a vida de outro que não age injustamente, ao passo que é um dever condicional preservar a própria vida. ${ }^{6}$ Ora, como se verá, a interpretação de Schopenhauer não deixa de ser a proposta que Rawls fará com a sua estratégia da posição original.

O próprio Kant tem uma formulação muito parecida com a regra de ouro, não do imperativo categórico, mas da ideia do contrato original, embora com mudanças muito importantes em relação à mesma, quem sabe, justamente para torná-la compatível com o imperativo categórico. Tal formulação ele a apresenta no texto Contra Hobbes escrito oito anos depois (1793) de sua crítica à regra de ouro na Fundamentação (1785). Segundo Kant, o contrato é uma ideia da razão que funciona como um pedra de toque de legitimidade da lei. Contudo, ela é dirigida ao legislador que tem que decidir de tal forma que o povo possa dar o seu consentimento à lei. Ou seja, não se trata de dar o consentimento a partir de desejos e inclinações, mas aquele que decide pelos outros tem que julgar como se eles pudessem dar o seu consentimento. Com efeito, se a bitola proposta fosse operacionalizada a partir da disposição presente no povo, então, provavelmente, não se instituiria nenhum imposto. Aliás, é o exemplo que Kant registra em nota à citação seguinte, o qual se anota na sequência. Segundo ele, o contrato, como uma ideia da razão,

obriga todo o legislador a fornecer as suas leis como se elas pudessem emanar da vontade colectiva de um povo inteiro, e a considerar todo o súbdito, enquanto quer ser cidadão, como se ele tivesse assentido pelo seu sufrágio a tal vontade. É esta, 
com efeito, a pedra de toque da legitimidade de toda a lei pública. Se, de facto, esta for de tal modo constituída que é impossível a um povo inteiro poder proporcionarlhe o seu consentimento (se, por exemplo, ela estabelece que uma certa classe de súbditos deve possuir hereditariamente o privilégio da nobreza), não é justa; mas se for apenas possível que um povo lhe dê o seu assentimento, então é um dever considerar a lei como justa: supondo também que o povo se encontra agora numa situação ou numa disposição do seu modo de pensar tal que, se ele fosse inquirido a seu respeito, recusaria provavelmente o seu consentimento (KANT, TP AA 08: 297).

Segundo Kant, a possibilidade de assentimento a uma lei é compatível com o caráter penoso da lei para o povo: "De facto, contanto que não haja contradição em que um povo inteiro dê por voto o seu assentimento a uma tal lei, por muito penoso que lhe seja aceitá-la, esta lei é conforme ao direito", " Com isso, Kant evita justamente uma objeção que ele fizera à regra de ouro na Fundamentação, qual seja, a de não fundamentar nenhum dever, especialmente os penosos.

Trata-se de uma alteração que é importante se for concedido que a formulação retro é uma dicção possível da regra de ouro. Como se percebe, ela se aproxima da concepção de razoabilidade de Rawls, como a determinação de ter que levar em consideração a racionalidade operante no outro, pois, sendo irracional para alguém concordar com menos do que o igual, não seria razoável esperar para si mais do que o igual, como mostra a citação abaixo. Portanto, avança-se a hipótese de que o contratualismo de Rawls introduz precisamente uma forma possível de evitar as muitas limitações que Kant sustentou estarem envolvidas na derivação da regra de ouro a partir do imperativo categórico. Feitas as correções necessárias na regra de ouro, ela se torna um exemplo de princípio razoável, ou seja, quem faz aos outros o que não faria a si mesmo, pode agir racionalmente, mas não está sendo razoável (RAWLS, 2007, p. 60). A razoabilidade, como já afirmado, segundo Rawls, é levar em consideração a racionalidade operante no outro, pois, sendo irracional para alguém concordar com menos do que o igual, não seria razoável esperar para si mais do que o igual: "Since it is not reasonable for him to expect more than an equal share in the division of social primary goods, and since it is not rational for him to agree to less, the sensible thing is to acknowledge as the first step a principle of justice requiring an equal distribution" (RAWLS, 1999, p. 130). Aceitar menos do que o igual para prejudicar os outros seria irracionalidade: "The special assumption I make is that a rational individual does not suffer from envy. He is not ready to accept a loss for himself if only others have less as well" (RAWLS, 1999, p. 130). 
Portanto, a possível compatibilidade entre a regra de ouro, - que opera por uma racionalidade estratégica, na medida em que a consideração do outro é feita a partir da consideração dos próprios interesses, - e o imperativo categórico, depende de haver as condições apropriadas para que tal racionalidade estratégica opere os resultados de razoabilidade esperados, ou seja, a igualdade e a reciprocidade. No caso de Hobbes, tais condições são postas pelo estado de natureza e, no caso de Rawls, pela posição original. Que condições são essas? Primeiro, para Rawls, as partes têm que ser consideradas racionais, no sentido de buscarem seus fins da maneira mais segura; para Hobbes, elas são racionais pelo interesse na sua autoconservação. Deveras, faz parte do argumento contra o louco no cap. XV do Leviathan que o homem queira "to defend himselfe from destruction". Se ele não quiser isso, o argumento não funciona. Contra aquele que não é avesso ao risco, ou que desafia a morte, não há argumentação possível. É o caso do homem-bomba. Deve-se somar a isso a incerteza que caracteriza os resultados do estado de natureza, bem como os resultados da posição original, ambos formulados por Rawls: "A general state of uncertainty about others" aims and intentions characterizes the State of Nature, so that a concern for our selfpreservation forces us to consider the worst possibilities" (RAWLS, 2007, p. 50); "The veil of ignorance leads directly to the problem of choice under complete uncertainty" (RAWLS, 1999, p. 149).

Em suma, a aproximação dos conceitos de estado de natureza em Hobbes e de posição original ocorre pelo menos por dois fatores. Um é aquele da incerteza dos resultados que caracteriza a ambos. O segundo fator é a definição das partes como sendo nem egoístas nem altruístas, mas como desinteressadas no bem dos outros (RAWLS, 1999, §3, p. 12). Mesmo em Hobbes, o que o homem busca é assegurar a sua vida. Se os outros puderem concomitantemente assegurar as deles não é um problema para o homem desinteressado no bem alheio. Com bem observa Rawls, o problema a ser resolvido na posição original, ou no estado de natureza, não se traduz em um jogo de soma-zero (RAWLS, 1999, §42. p. 238). É por isso exatamente que a justiça só é possível quando a escassez econômica for moderada. Porque se ela for severa, será um jogo de soma-zero, não sendo, portanto, possível se falar em justiça.

A particularidade de Rawls está no tipo de incerteza envolvida. No caso de Hobbes, a incerteza considerada é com relação à morte. No caso de Rawls, a incerteza é mais diversificada do que em Hobbes, pois ela se refere, como visto, à incerteza com relação à religião à qual se pertencerá, ao sexo que se terá, à classe econômica da qual se fará parte, à 
cor da pele que se terá. Portanto, os conteúdos que resultarão de um cálculo que busca evitar tais incertezas será muito próximo do que pede o imperativo categórico, o qual ordena que se considere a normatividade independentemente de qualquer circunstância. Pois bem, a posição original realiza a desconsideração de algumas circunstâncias no cálculo do conteúdo, circunstâncias que historicamente se mostraram impróprias para tratar dos conteúdos da justiça.

Desse modo, para se entender o neocontratualismo de Rawls, há que se ter presente que o papel do imperativo categórico é assumido pelo procedimento da posição original, como visto na citação (b), acima. O ponto que permite conectar Kant com o argumento da posição original é que a igualdade dos eus [selfs] é equivalente a ter princípios de justiça aceitáveis por outros eus (RAWLS, 1999, §40, p. 226). Do princípio da igualdade se segue que todos devem ter uma igualdade de voz [equal say] na adoção de princípios comuns, o que significa dizer que todos têm que consentir com os princípios: "everyone is to consent to these principles" (RAWLS, 1999, p. 226). Rawls, defende que poder-se-ia chegar a tal resultado a partir do eu singular, pois a unanimidade desse consenso poderia ser também a melhor expressão da natureza até mesmo de um único eu "I shall try to define a clear sense in which this unanimous agreement is best expressive of the nature of even a single self' (RAWLS, 1999, p. 226), logo, o teste pode ser operacionalizado a partir desse eu. Ora, é isso justamente que a posição original opera. Ela converte uma decisão estrategicamente considerada, em um conteúdo moral. Eis o que Rawls afirma:

The veil of ignorance is so natural a condition that something like it must have occurred to many. The formulation in the text is implicit, I believe, in Kant's doctrine of the categorical imperative, both in the way this procedural criterion is defined and the use Kant makes of it. Thus when Kant tells us to test our maxim by considering what would be the case were it a universal law of nature, he must suppose that we do not know our place within this imagined system of nature (RAWLS, 1999, p. 118).

Um texto de Hampton sufraga essa tese da relação entre Kant, Rawls e Hobbes:

defining the content of justice by determining what the subjects in a society can all 'agree to' is an idea first proposed explicitly by Kant and developed later by such philosophers as Rawls. But is an idea that is already implicit in the Hobbesian fallback position, because in this view, in order for the subjects to maintain a ruler in 
power, they must agree in fact, either explicitly or implicitly, on the details of a standard by which to judge the ruler's performance, where this standard will influence how a ruler - who is concerned to please her subjects so as to stay in power - will legislate (HAMPTON, 1986, p. 246).

Em relação à regra de ouro, de base egocêntrica, o imperativo categórico requer que todos possam querer a máxima. O que é bom para todos é bom para alguém em particular, mas nem tudo o que é bom para alguém em particular é bom para todos. Para que o bom para todos possa ser deduzido por um procedimento que opere a partir do que é bom para alguém em particular são necessárias certas condições, como aquelas que Ralws propõe com o véu de ignorância e como as que Hobbes propõe ao imputar aos indivíduos um desejo de autoconservação. Nisso se pode perceber como a argumentação de Rawls se adéqua à crítica feita por Schopenhauer, como acima declinado.

Como sustenta Moehler, "the methodologically opposed moral approaches of Hobbes and Kant may converge on a similar moral conclusion (MOEHLER, 2011, p. 02), qual seja, a universalidade, ainda que sob a forma da regra de ouro, especialmente em sua versão negativa. Ambos teriam em comum uma universalidade fraca: "The weak principle of universalization represents a generalized and universalized statement of the stabilized Nash bargaining solution” (MOEHLER, 2011, p. 19). Em teoria dos jogos um tal equilíbrio ocorre quando a mudança unilateral por qualquer um piora a sua própria situação, o que significa que o jogo se equilibra porque ninguém terá interesse em mudar a sua decisão unilateralmente (MOEHLER, 2009). Assim, "Despite its thoroughly non-Kantian justification, the weak principle of universalization can be seen as a weak version of Kant's categorical imperative because the principle weakly expresses the core moral ideals, such as autonomy, impartiality, and equality, which underlie the categorical imperative" (MOEHLER, 2011, p. 20). No mesmo sentido, Lloyd propõe a sua interpretação de Hobbes a partir do teorema da reciprocidade que ela chama de "a weak universality requirement" (LLOYD, 2009, p. 230), o qual ela mesma sugere ter parentesco com a universalidade kantiana.

Nessa empreitada, como sustentado, a posição original é que desempenha o papel central, pois "como elas [as partes na posição original] não sabem que posições ocuparão no futuro, na sociedade por elas ordenada, seu próprio interesse leva-as a pensar a respeito do que seja uniformemente bom para todos" (HABERMAS, 2004, p.64). Segundo uma tal formulação, 
The Rawlsian 'veil of ignorance' forces rational individuals to make moral choices. That is, although individuals in Rawls' idealized decision situation, which Rawls calls the 'original position', do not have to be moral beings, the moral ideals that Rawls wants to be expressed by the principles of justice to be derived in the original position are enforced by the structure of his hypothetical decision situation (MOEHLER, 2011, p. 13).

Que um mesmo conteúdo possa ter fundamentos diferentes é um pressuposto ao qual Rawls continua fiel em toda a sua obra, ainda que de um modo mais amplo em obras tardias. Ou seja, não se trata mais de afirmar que os conteúdos de justiça possam ser justificados só pelo imperativo categórico, ou só por uma estratégia contratual com base na regra de ouro adequadamente compreendida: "in such a consensus, the reasonable doctrines endorse the political conception, each from its own point of view" (RAWLS, 1996, p. 134). Ou seja, "different premises can yield the same conclusion. In this case there exists what we may refer to as overlapping rather than strict consensus" (RAWLS, 1999, p. 340). Aliás, é precisamente esse ponto a partir do qual Lloyd conecta a filosofia de Hobbes com aquela de Rawls (LLOYD, 2009, p. 406). Portanto, assim como em Rawls os princípios de justiça podem ser justificados considerando várias perspectivas, ou seja, a partir do equilíbrio reflexivo amplo como consenso sobreposto, a partir da posição original e pela razão pública (HEDRICK, 2010, cap. 2), assim também ocorreria em Hobbes:

The triple status of the Laws of Nature as precepts of prudence, requirements of morality, and dictates of natural religion provides a substantial area of overlap among virtually all comprehensive doctrines, which could support Hobbes's principle of political obligation without further reliance on any controversial aspects of sectarian doctrine. (LLOYD, 2009, p. 406).

Em suma, Hobbes pode ser aproximado de Rawls ao menos sob um duplo ponto de vista. Uma aproximação é aquela entre a estratégia da posição original e o argumento a partir do estado de natureza. A outra aproximação é em relação à neutralidade da ordem social defendida por Hobbes, o que porta conexão com o argumento do consenso sobreposto.

Por fim, no que concerne a Kant, pode-se considerar haver uma sobreposição entre os conteúdos gerados pelo imperativo categórico, ou pelo princípio universal do direito, e a substância normativa contida nas leis naturais. Rawls foi utilizado no presente texto como 
uma mediação entre Kant e Hobbes. Tentou-se tornar plausível tal estratégia mediante o argumento rawlsiano da posição original, na medida em que este pode ser interpretado como uma formulação do argumento a partir do estado de natureza e a partir do imperativo categórico. O contratualismo de Rawls, tal qual ele se apresenta no argumento da posição original, é suficientemente complexo para permitir uma aproximação com Kant e Hobbes em relação à estratégia de construção dos conteúdos, bem como sob o ponto de vista do próprio conteúdo. Melhor dito, a posição original é uma estratégia de construção de conteúdos de justiça que permite aproximar o imperativo categórico e o argumento a partir do estado de natureza.

\section{Kant e Hobbes: paz e autoconservação}

Interessantemente, a objeção que Kant faz a tais imperativos hipotético-assertóricos não é com relação à certeza do fim, pois este ele o considera um fim real, cujo argumento da necessidade natural é suficiente para provar. O que ele alega, na verdade, é que o fim da felicidade é indeterminado. Ora, ao fim da autoconservação, que Hobbes interpreta como sendo um fim real que pode ser atribuído a todos com a mesma necessidade que Kant atribuiu á felicidade, não se pode atribuir tal objeção, pois ele é um fim determinado para o qual a razão pode fornecer os meios precisos, quais sejam, as leis naturais. Essa afirmação depende de duas teses: a primeira é que a finalidade da ordem civil seja a autoconservação e que esta não seja um outro nome para a felicidade; a segunda é que não haja grande diferença entre os conteúdos da lei natural e aquilo que ordena o princípio do direito em Kant.

Em relação à primeira tese, Kant não acusa diretamente Hobbes de ter posto a felicidade como fundamento do contrato, contudo, ele parece sugerir essa interpretação (AIRAKSINEN, SIITONEN, 2004). Para tal, basta ver os dois primeiros parágrafos de seu texto Contra Hobbes, bem como a crítica ao despotismo e ao paternalismo que ele desfila no texto. Contudo, não há indício textual forte de que Hobbes tenha posto a felicidade como fundamento do contrato. Ele, certamente, não negou que a felicidade se constitua em um objeto dos desejos humanos, como se mostra o próprio cap. XI do Leviathan, porém ele parece sugerir que as discordâncias com relação a tal matéria deveriam forçar as partes a buscarem um fundamento menos contestável e contestado. Tal parece residir na autoconservação. 
Em relação à segunda tese, de que não há grande diferença quanto aos conteúdos da lei natural e aquilo que ordena o princípio do direito em Kant, isso é verdade não só em relação à igualdade e à liberdade, para o que basta verificar a segunda lei de natureza em Hobbes, quanto é verdade no que concerne à obediência ao soberano. De fato, se é verdade que Kant critica o fato de Hobbes ter defendido que o soberano não pode errar na interpretação do direito, é também verdadeiro que, para ele, mesmo a interpretação do direito estando errada, o súdito tem que obedecer, ainda que possa criticar publicamente o erro.

Certamente, há discordância quanto ao fundamento, que para Kant é a priori e para Hobbes reside na autoconservação, porém, é necessário perscrutar no que Kant poderia discordar com relação à necessidade de a doutrina do direito considerar a autoconservação. Ora, não se vê no que Kant possa objetar no que concerne ao conteúdo. Para Hobbes, a suma da lei natural é a paz, um outro nome para a autoconservação. Para Kant, a finalidade última do direito é a paz, ditada pela razão:

\begin{abstract}
Pode-se dizer que esta fundação da paz universal e permanente não perfaz apenas uma parte, mas todo o fim terminal da doutrina do direito nos limites da simples razão, pois somente o estado de paz é o estado do meu e teu assegurado por leis em uma multidão de homens avizinhados, portanto reunidos em uma constituição, cuja regra não deve, contudo, ser tirada da experiência daqueles que até agora se deram melhor, como uma norma para outros, mas derivada a priori pela razão do ideal de uma associação jurídica dos homens sob leis públicas em geral (KANT, 2005, p. 355); (RL, AA 06: 355).
\end{abstract}

Como bem anota Loparic, "O objetivo último total — e não o inicial e apenas parcial — da doutrina do direito, elaborada nos limites da mera razão, é o estabelecimento da paz universal e permanente" (LOPARIC, 2003, p. 477-520). Pois bem, uma paz sem a autoconservação seria a paz dos cemitérios. Dito lapidarmente, um sistema que torne possível um sistema de liberdade tem que conservar a vida de seus membros no sentido de Hobbes, ou seja, tem que abolir ou reduzir a um mínimo o homicídio. Não há como ser livre estando morto. No caso de Kant, a finalidade da paz, como objetivo da razão, incorpora de forma depurada, sublimada, os ditames da autoconservação, pois, como poderia haver paz se a autoconservação não estivesse assegurada?

Há que se observar que para Kant o funcionamento das paixões leva ao mesmo resultado da moral em relação ao conteúdo, ainda que o coração humano possa permanecer 
empedernido, o que torna a resolução do problema da constituição de um Estado possível até para a raça de demônios:

\begin{abstract}
Mas vem então a natureza em ajuda da vontade geral, fundada na razão, respeitada mas impotente na prática, e vem precisamente através das tendências egoístas, de modo que dependa só de uma boa organização do Estado (a qual efectivamente reside no poder do homem) a orientação das suas forças, a fim [29] de que umas detenham as outras nos seus efeitos destruidores ou os eliminem: o resultado para a razão é como se essas tendências não existissem e, assim, o homem está obrigado a ser um bom cidadão, embora não esteja obrigado a ser moralmente um homem bom. (KANT, ZeF, AA 08: 365-366).
\end{abstract}

Dizer que o direito racional tem como determinação a paz não torna o princípio universal do direito de Kant um imperativo hipotético. Também não se pode dizer que a pacificação que o direito opera não tenha como consequência tornar possível a autoconservação de cada um, evitando a morte violenta e garantindo a propriedade. Portanto, difícil ver no que o conteúdo da lei natural hobbesiana divergiria do conteúdo das condições que tornam possível a convivência em Kant, de acordo com o princípio universal do direito.

$\mathrm{Na} \mathrm{KrV}$, Kant parece concordar com Hobbes: "Tal como Hobbes afirma, o estado de natureza é um estado de violência e de prepotência e devemos necessariamente abandoná-lo para nos submetermos à coação das leis, que não limita a nossa liberdade senão para que possa conciliar-se com a liberdade de qualquer outro e, desse modo, com o bem comum" (KANT, 2002, B780). Segundo Gauthier, as leis de natureza em Hobbes não limitam o direito natural, mas prescrevem como empregar tal direito (GAUTHIER, 1969, p. 53). Não estabelecem que o direito natural deva ser completamente limitado, mas limitado em alguns aspectos, mormente naqueles que importam para a paz (GAUTHIER, 1969, p. 54). Como bem observa o próprio Hobbes, a liberdade é "aquela parte do direito de natureza que é reconhecida e deixada aos súditos pelas leis civis" (HOBBES, 1998, p. 107). Uma tal liberdade é o registro daquilo que é inofensivo ao Leviathan: "Constitui parte substancial dessa liberdade, que é inofensiva ao governo civil, e necessária para que cada súdito viva em felicidade, que não haja penalidades a temer, a não ser as que ele possa tanto antever quanto esperar" (HOBBES, 1998, p. 107).

Logo, não se vê no que Kant poderia discordar de Hobbes nesse ponto. Obviamente, Kant poderia afirmar que um sistema de escravidão também asseguraria a vida. A isso Hobbes poderia alegar que não é o meio que a razão indica para a consecução da paz, pois não se 
estabelece vínculo obrigacional entre as partes se uma delas for escrava, tornando o sistema instável: "for such men, (commonly called Slaves,) have no obligation at all" (HOBBES, 1968, chap. XX). Ou seja, Hobbes aponta a liberdade igual entre os súditos como o único meio para a paz e a autoconservação. Isso é claro, por exemplo, na segunda lei de natureza, bem como na própria formulação da regra de ouro que é a suma das leis naturais.

Uma objeção a essa interpretação seria aquela de que a sociedade só se constituiria se o fundamento fosse o dever de não matar em vez do direito de se autodefender. Indícios de uma tal perspectiva podem ser encontrados na recusa kantiana de um direito no estado de necessidade, tanto na Doutrina do direito quando em Contra Hobbes. Porém, esse é tema para um outro estudo. 


\section{Notes:}

1 Professor da Universidade Federal de Santa Catarina, Florianópolis, Santa Catarina, Brasil. E-mail: djvdutra@yahoo.com.br. O autor agradece à CAPES pela bolsa "Estágio sênior no exterior" concedida no período de agosto de 2011 a julho de 2012 para o projeto de pesquisa "As críticas de Habermas a Kant e a Hobbes", realizado junto à Aberystwyth University, Wales, UK, em colaboração com Howard Williams. O autor agradece, também, à UFSC e ao seu Departamento de Filosofia pelo afastamento concedido no período mencionado.

${ }^{2}$ Sobre a tese kantiana do positivismo moral em Hobbes ver: (PAVÃO, 2006, p. 79-92)

3 "Indeed, Hobbes actually goes as far as to anticipate Kant's attempt to reduce all really wrong willing to the irrational attempt to will both sides of a contradiction at once." (TAYLOR, 1938, p. 409)

${ }^{4}$ Essa reformulação do direito natural clássico já tinha sido sugerida por Grotius, que estabeleceu três sentidos para o termo direito: primeiro, como o que é justo; segundo, uma faculdade ou poder que se tem sobre si mesmo, chamada de liberdade; terceiro, como a lei que nos obriga a fazer o que é apropriado (GROTIUS, 2001, Book I, chap. I, III, V e IX, respectivamente). A esse respeito ver: (VOLPATO DUTRA, 2011).

5 (HÖFFE Apud HABERMAS, 1997, p. 125, nota 20; HÖFFE, 1992, p. 120-142).

${ }^{6}$ (KANT, Immanuel. Sobre a expressão corrente: isso pode ser correcto na teoria, mas nada vale na prática. [Trad. Artur Morão]. Covilhã: Lusofia Press, $\quad$ s/d [1793]. [http://www.lusosofia.net/textos/kant_immanuel_correcto_na_teoria.pdf/], p. 31-32); (TP, AA 08: 300 nota).

${ }^{7}$ KANT, Immanuel. Sobre a expressão corrente: isso pode ser correcto na teoria, mas nada vale na prática. [Trad. Artur Morão]. Covilhã: Lusofia Press, $\quad$ s/d [1793]. [http://www.lusosofia.net/textos/kant_immanuel_correcto_na_teoria.pdf /], p. 30 [TP, AA 08: 299; KANT, Immanuel. A paz perpétua: um projeto filosófico. [Trad. Artur Morão]. Covilhã: Lusofia Press, 2008 [1795]. [http://www.lusosofia.net/], p. 11 nota 4 [ZeF, AA 08: 350. 


\section{Referências bibliográficas:}

AIRAKSINEN, Timo, SIITONEN, Arto. Kant on Hobbes, Peace, and Obedience. History of European Ideas. V. 30, 2004, p. 315-328.

BARBOSA FILHO, Balthazar. Condições da autoridade e autorização em Hobbes. Filosofia Política 6. Porto Alegre: L\&PM, 1991, p. 63-75.

BERTEN, André. Habermas crítico de Rawls: a posição original do ponto de vista da pragmática universal. In: BOMBASSARO, Luiz Carlos, PAVIANI, Jayme [orgs.]. Filosofia, lógica e existência: homenagem a Antonio Carlos Kroeff Soares. Caxias do Sul: EDUCS, 1997, p. 24-47.

. Por que Habermas não é e não pode ser um contratualista? In. PINZANI, Alessandro, VOLPATO DUTRA, Delamar. Habermas em discussão. Anais do Colóquio Habermas realizado na UFSC (Florianópolis, 30 de março $-1^{\circ}$. de Abril de 2005). Florianópolis: NÉFIPO, 2005, p. 128-142.

BURGESS, Glenn. Hobbesian Resistance Theory. Political Studies. V. 42, n. 1, 1994, p. 62 83.

DARWALL, Stephen. The British Moralists and the Internal 'Ought': 1640-1740. Cambridge: Cambridge University Press, 1995, p. 76.

GAUTHIER, David. The Logic of Leviathan. Oxford: Clarendon Press, 1969.

GREGOR, Mary J. Law of Freedom: A Study of Kant's Method of Applying the Categorical Imperative in the 'Methapysik der Sitten'. Oxford: Blackwell, 1963.

GROTIUS, Hugo. On the Law of War and Peace. [1625]. (Transl. A. C. Campbell: De jure belii ac pacis). Botoche: Ontario, 2001, Book I, chap. 1, III, V e IX, respectivamente]

HABERMAS, Jürgen. The Inclusion of the Other: Studies in Political Theory. [Transl. Ciaran Cronin: Die Einbeziehung desanderen Studien zur politischen Theorie]. Cambridge: MIT Press, 1998 [1996], p. 52.

Direito e democracia: entre faticidade e validade. [v. I e II]. [Trad. F. B. Siebeneichler: Faktizität und Geltung: Beiträge zur Diskurstheorie des Rechts und des demokratischen Rechtsstaats]. Rio de Janeiro: Tempo Brasileiro, 1997.

Faktizität und Geltung: Beiträge zur Diskurstheorie des Rechts und des demokratischen Rechtsstaats. 4. Auflage, Frankfurt am Main: Suhrkamp, 1994.

Justification and Application: Remarks on Discourse Ethics. [Transl. Ciaran Cronin: Erläuterungen zur Diskursethik]. Cambridge: The MIT Press, s/d [1991], p. 27]. 
HAMPTON, Jean. Hobbes and the Social Contract Tradition. Cambridge: Cambridge University Press, 1986. Hobbes não consegue justificar o absolutismo.

HEDRICK, Todd. Rawls and Habermas: Reason, Pluralism, and the Claims of Political Philosophy. Stanford: Stanford University Press, 2010.

HERBERT, Gary B. The Non-normative Nature of Hobbesian Natural Law. Hobbes Studies. V. 22, 2009, p. 3-28.

HOBBES, Thomae. De Cive. Oxford: Clarendon, 1983 [1642].

Do cidadão. [R. J. Ribeiro: Philosophical Rudiments Concerning Government and

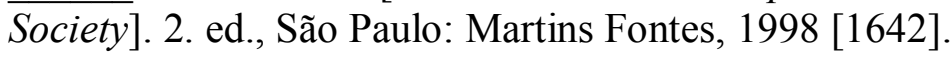

Leviathan, or Matter, Form, and Power of a Commonwealth Ecclesiastical and Civil.

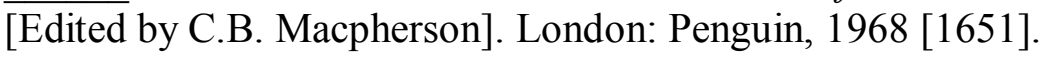

HÖFFE, Otfried. 'Even a Nation of Devil Needs the Satate': the Dilemma of Natural Justice. In: WILLIAMS, Howard Lloyd [ed.]. Essays on Kant's Political Philosophy. Chicago: The University of Chicago Press, 1992. p. 120-142.

HÜNING, Dieter. Hobbes on the Right to Punish. In SPRINGBORG, Patricia [Ed.]. The Cambridge Companion to HOBBES'S LEVIATHAN. Cambridge: Cambridge University Press, 2007, p. 217-242.

KANT, Immanuel. A metafísica dos costumes. [Tr. J. Lamego]. Lisboa: Fundação Calouste Gulbenkian, 2005.

A paz perpétua e outros opúsculos. (Trad. A. Morão). Lisboa: E. 70, 1988.

Crítica da razão prática. (Trad. Valério Rohden: Kritik der praktischen Vernunft). São Paulo: Martins Fontes, 2002.

Sobre a expressão corrente: isso pode ser correcto na teoria, mas nada vale na $\overline{\text { prática. }}$ [Trad. Artur Morão]. Covilhã: Lusofia Press.[Disponível em: http://www.lusosofia.net/textos/kant_immanuel_correcto_na_teoria.pdf].(KANT, TP, AA 08)

Fundamentação da metafísica dos costumes. [Trad. G. A. de Almeida: Grundlegung zur Metaphysik der Sitten]. São Paulo: Discurso Editorial/Barcarolla, 2009.

KAUFMAN, Alexander. Rawls and Kantian Constructivism. Kantian Review. V. 17, Issue 02, 2012, p 227-256.

KAVKA, Gregor. The Rationality of Rule-Following: Hobbes' Dispute with the Foole. Law and Philosophy. V. 14, 1995.

LLOYD, Sharon. A. Hobbes's Self-effacing Natural Law Theory. Pacific Philosophical Quarterly. V. 82, n. 3-4, 2001, p. 285-308. 
LLOYD, S. A. Morality in the Philosophy of Thomas Hobbes: Cases in the Law of Nature. Cambridge: Cambridge University Press, 2009.

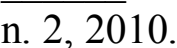

The Moral Philosophy of Thomas Hobbes: A Reply to Critics. Hobbes Studies. V. 23,

LOPARIC, Zeljko. O problema fundamental da semântica jurídica de Kant. In WRIGLEY, Michael B., SMITH, Plínio J. O filósofo e sua história: uma homenagem a Oswaldo Porchat. [Coleção CLE, v. 36]. Campinas: UNICAMP, 2003, p. 477-520.

MILL, John Stuart. Utilitarianism and On Liberty. Including Mill's 'Essay on Bentham' and selections from the writings of Jeremy Bentham and John Austin. [Ed. with an Introduction by Mary Warnock]. 2. Ed., Oxford: Blackwell, 2003.

MOEHLER, Michael. A Hobbesian Derivation of the Principle of Universalization. Philosophical Studies. V. 158, n.1, 2011, p. 83-107.

Why Hobbes' State of Nature is Best Modeled by an Assurance Game. Utilitas. N. 21, 2009, p. 297-326.

NAGEL, Thomas. Hobbes's Concept of Obligation. Philosophical Review. V. 68, 1959, p. 68-83.

PAVÃO, Aguinaldo. Hobbes e a moralidade: a leitura kantiana. Dissertartio. N. 24, 2006, p. 79-92. [Disponível em http://ich.ufpel.edu.br/depfil/filesdis/dissertatio24.pdf ].

RAWLS, John. A Theory of Justice. [Revised Edition]. Oxford: Oxford University Press, 1999a [1971].

. The Law of Peoples. Cambridge: Harvard University Press, 1999b.

Press, 2007.

Lectures on the History of Political Philosophy. Cambridge, MA: Harvard University

. Political Liberalism. New York: Columbia University Press, 1996 [1993].

ROUSSEAU, Jean-Jacques. Du contrat social. Paris: Aubier, 1943 [1757].

SCHOPENHAUER, Arthur. Sobre o fundamento da moral. [Trad. M. L. M. O. Cacciola]. São Paulo: Martins Fontes, 2001.

TAYLOR, A. E. The Ethical Doctrine of Hobbes. Philosophy. V. 13, n. 52, 1938.

VOLPATO DUTRA, Delamar José. Grotius: pré-história da teoria kantiana da virtude. Dissertatio. V. 33, 2011b, p. 439-453.

VOLPATO DUTRA, Delamar José. Grotius: pré-história da teoria kantiana da virtude. In HOBUSS, João (Org.). Ética das virtudes. Florianópolis: EDUFSC, 2011c, p. 157-169. 
WARRENDER, Howard. The Political Philosophy of Hobbes. Oxford: Oxford University Press, 1957.

WILLIAMS, Howard. Kant's Critique of Hobbes. University of Wales Press, 2003. 